\title{
An exploration of the experience of compassion fatigue in clinical oncology nurses
}

by Beth Perry, Greg Toffner, Trish Merrick and Janice Dalton

\begin{abstract}
Compassion fatigue (CF) is "debilitating weariness brought about by repetitive, empathic responses to the pain and suffering of others" (LaRowe, 2005, p. 21). The work performed by oncology nurses, and the experiences of the people they care for, place oncology nurses at high risk for CF (Pierce et al., 2007; Ferrell \& Coyle, 2008). Thus oncology nurses were chosen as the study focus. This paper details a descriptive exploratory qualitative research study that investigated the experience of $C F$ in Canadian clinical oncology registered nurses (RNS). A conceptual stress process model by Aneshensel, Pearlin, Mullan, Zarit, and Whitlatch (1995) that considers caregivers' stress in four domains provided the study framework (see Figure 1). Nineteen study participants were recruited through an advertisement in the Canadian Oncology Nursing Journal (CONJ). The advertisement directed potential participants to a university-based online website developed for this study. Participants completed a questionnaire and wrote a narrative describing an experience with CF and submitted these through the secure research website. Data were analyzed thematically. Five themes include: defining $C F$, causes of $C F$, factors that worsen CF, factors that lessen CF, and outcomes of CF. Participants had limited knowledge about CF, about lack of external support, and that insufficient time to provide high quality, care may precipitate CF. The gap between quality of care nurses wanted to provide and what they were able to do, compounded by coexisting physical and emotional stress, worsened CF. CF was lessened by colleague support, work-life balance, connecting with others, acknowledgement, and maturity and experience. Outcomes of CF included profound fatigue of mind and body, negative effects on personal relationships, and considering leaving the specialty. Recommendations that may enhance oncology nurse well-being are provided.
\end{abstract}

Cancer is a serious life-threatening disease, which often involves physical, emotional, and/or spiritual suffering. Oncology nurses carry much of the responsibility for providing care to these individuals. The complexity of the care required, combined with the potential intensity of nurse-patient relationships in an oncology setting, may place cancer nurses at high risk for $\mathrm{CF}$ and, thus, they are the focus of this study. Yet, despite this risk, CF remains a largely unexplored phenomenon in this group (Bush, 2009). This descriptive exploratory qualitative research investigated the experience of $\mathrm{CF}$

\section{About the authors}

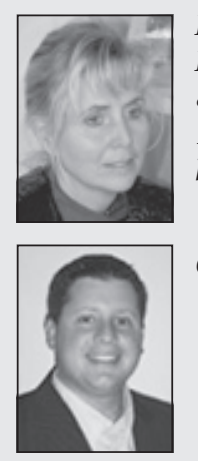

Beth Perry, RN, PhD, Associate Professor, Centre for Nursing and Health Studies, Athabasca University, 8708-116 Ave., Edmonton, AB T5B OM6. Phone: 1-866-804-7721; Fax: 780-675-6468. Email: bethp@athabascau.ca

Greg Toffner, BSC, MRT(R), RTR, MHS (candidate)

Trish Merrick, $R N, B S c N$

Janice Dalton, RD, MHS in clinical oncology nurses in Canada. The study data revealed how oncology nurses define $\mathrm{CF}$, factors that cause, worsen and/or lessen $\mathrm{CF}$, and outcomes of $\mathrm{CF}$ in this group. A conceptual stress process model that considers caregivers' stress in four domains provides a framework for analysis and recommendations (Aneshensel et al., 1995) (see Figure 1). This study is significant because it explores a phenomenon that may have a negative impact directly on the wellbeing of oncology nurses, and indirectly on the people they care for. Nurses who are not fully healthy themselves cannot provide optimum care (Perry, 2009). Understanding more about CF in oncology nurses is the first step in developing and implementing strategies to prevent or minimize CF in these caregivers.

\section{Literature review}

Compassion fatigue defined. Compassion fatigue was first used by Joinson in 1992 to describe the unique stressors that affect people in care giving professions. LaRowe (2005) described CF as "debilitating weariness brought about by repetitive, empathic responses to the pain and suffering of others" (p. 21). Bush (2009) elaborates describing $\mathrm{CF}$ as an emotional state with negative psychological and physical consequences that emanate from acute or prolonged care giving to people stricken by intense trauma, suffering, or misfortune.

Although well defined, conceptual confusion regarding $\mathrm{CF}$ remains. CF is one of an array of terms used to describe the effects of caring for people experiencing trauma (Abendroth \& Flannery, 2006). Other terms sometimes used interchangeably with CF include vicarious traumatization (VT), secondary traumatic stress disorder (STSD), post-traumatic stress disorder (PTSD), moral distress (MD), and burnout (Ferrell \& Coyle, 2008; Munroe, 1995; Sabo, 2006; Davis, 1996). What these syndromes, including CF, have in common is an emphasis on the physical and psychological price of caring experienced by caregivers. The consensus is that regardless of the label, working with people experiencing life-threatening illness and suffering can have harmful consequences for caregivers (Abendroth \& Flannery, 2006).

CF differs from these other syndromes that affect caregivers (Bush, 2009). For example, in VT, STSD and PTSD, the caregiver is exposed specifically to a traumatic event(s), while in CF the exposure is to a traumatized person and there is an unconscious absorp-

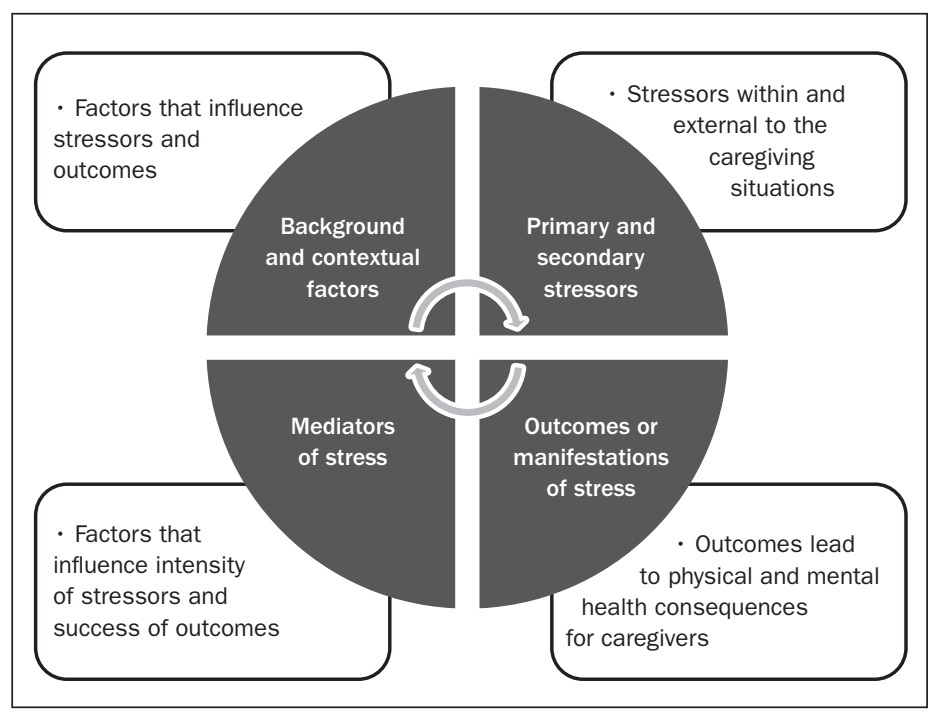

Figure 1. Stress Process Model

Adapted from (Aneshensel, Pearlin, Mullan, Zarit, \& Whitlatch, 1995) 
tion of that person's trauma (Sabo, 2006). Further, CF and burnout are not the same although the existence of burnout is thought to increase the likelihood of developing CF (Sabo). CF is considered a "natural" consequence of caring for people who are suffering, while burnout is a response to negative work environment triggers such as workload and the inability to achieve work goals (Sabo). While burnout involves a gradual wearing down of the caregiver, the onset of CF is often more acute (Magraith, Benson, \& Yunti, 2005). Some believe that burnout can be treated by being away from workplace triggers, while $\mathrm{CF}$ can have longer lasting negative consequences for the caregiver and the treatment is not clear (Sabo, 2006). Moral distress relates to ethical challenges experienced in caring for seriously ill people when caregivers know the "right" thing to do, but do not do it (Davis, 1996). While CF may be exacerbated by MD, CF is considered a distinct experience (Sabo, 2006). Nurses find CF to be most reflective of their experience of working with people who are suffering (Sabo, 2006). Therefore, CF was chosen as the focus for this study.

Researchers conclude that CF occurs in a variety of health care professions including, but not limited to social work, clinical research, occupational and physical therapy, genetic counselling and medicine (Adams, Figley, \& Bascarino, 2008; Badger, Royse, \& Craig, 2008; Pickett, Brennan, \& Greenberg, et al., 1994; Stebnicki, 2002; Costa,

\section{Table 1. Summary of study participants demographics}

\section{Age Range of Participants}

\begin{tabular}{|l|l|}
\hline Age & Number \\
\hline $20-30$ & 3 \\
\hline $31-40$ & 7 \\
\hline $41-50$ & 4 \\
\hline $51-60$ & 5 \\
\hline Total & 19 (all female) \\
\hline
\end{tabular}

\section{Work experience}

\begin{tabular}{|l|l|l|l|l|}
\hline Years of Experience & Min. & Max. & Mean & Median \\
\hline As a Registered Nurse & 2 & 33 & 17.16 & 17 \\
\hline As an Oncology Nurse & 2 & 23 & 9.47 & 9 \\
\hline
\end{tabular}

Clinical experience

\begin{tabular}{|l|l|}
\hline Practice Environment & Number \\
\hline Practicing in Oncology & 11 \\
\hline Not Practicing in Oncology & 5 \\
\hline No Response & 3 \\
\hline
\end{tabular}

\section{Educational qualifications}

\begin{tabular}{|l|l|l|l|l|}
\hline & RN & BA & $\begin{array}{l}\text { Master of } \\
\text { Science }\end{array}$ & Doctorate \\
\hline Education & 6 & 10 & 3 & 0 \\
\hline Advanced Certification (total number) \\
\hline Hold an Oncology Certification & 3 \\
\hline No Oncology Certification & 15 \\
\hline No Response & 1 \\
\hline
\end{tabular}

2005; Benoit, McCarthy Veach, \& LeRoy, 2007; Pfifferling, \& Gilley, 1999). Studies show that nurses are at particular risk for CF because compassion and empathy are core values nurses employ in order to do their work (Figley, 1995). Enacting these values makes RNs at risk for being "wounded by their work" (Stebnicki, 2002). Empathy can be viewed as a double-edged sword, a necessary core value for a nurse and a point of vulnerability at the same time (Larson, 1993). Perhaps the compassionate qualities that attract nurses to their profession also make them vulnerable to CF (Bush, 2009).

Although oncology nurses may be at particularly high risk for $\mathrm{CF}$, there are very few studies related to CF in this group (Bush, 2009; McMullen, 2007). Existing studies of CF in oncology nurses are preliminary. For example, Pierce et al. (2007) found that oncology nurses are unfamiliar with the term CF and associated symptoms. Absolon and Krueger (2008) studied the effectiveness of a CF nursing support group specific to gynecology/oncology nurses. Based on limited research evidence Aycock and Boyle (2008) suggested interventions to manage CF in oncology nurses. In summary, the nature of their work, and the experiences of patients they care for, makes cancer nurses at high risk for CF. Yet, there is a dearth of research to aid our understanding of the experience of CF in this population (Ferrell \& Coyle, 2008).

Health consequences of CF. Limited research has explored the potential health consequences of caring work on nurses (Abendroth \& Flannery, 2006; Sabo, 2008). Existing explorations propose that CF may have a profound negative impact on caregiver mental and physical health (Sabo, 2008; Figley, 1995). Effects of CF may occur on a continuum from acute to chronic and affect seven domains: cognitive, emotional, behavioural, personal relations, somatic, work performance, and spiritual (Figley, 1995). Cognitive symptoms may include decreased concentration, low self-esteem, and apathy (Maslach, Jackson, \& Leiter, 1996). Emotional symptoms include anxiety, guilt, depression, anger, and powerlessness (Bush, 2009). Behavioural symptoms include irritability, appetite changes, and fatigue (Maslach et al., 1996). CF affects personal relations because of mistrust of others and withdrawal (Bush, 2009). Somatic complaints range from generalized pain to impaired immunity (Maslach et al., 1996). Nurses may experience spiritual symptoms from CF such as questioning of the meaning and purpose of life and doubting personal beliefs and values (Bush, 2009). In sum, nurses experiencing CF may find they are unable to work effectively and may experience permanent unhealthy changes in their views of self, others and work (Bush, 2009). Further, the cumulative influences of CF can damage personal and professional health, lead to deep emotional and physical exhaustion, and cause nurses to question the value of the work they do (Robinson, Clements, \& Land, 2003).

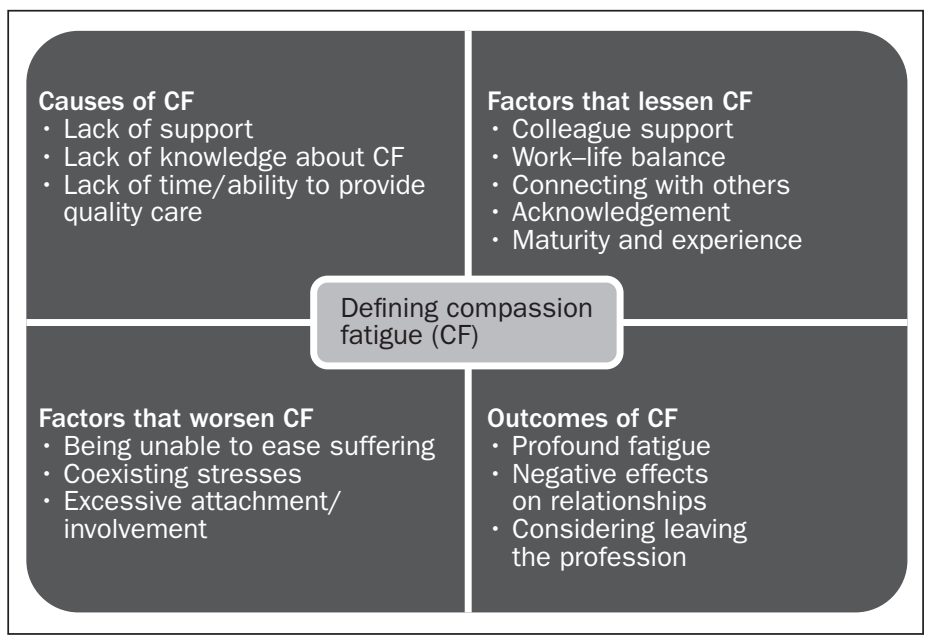

Figure 2. Map of Study Findings 


\section{Methods}

This descriptive exploratory qualitative study targeted the experience of CF in Canadian clinical oncology RNs. The purpose of the study was to explore how Canadian clinical oncology registered nurses (RNs) described their experiences of CF. Study findings may inform further research on this topic. The study focus was narrowed to include factors that cause, worsen, and/or lessen CF in clinical oncology nurses. The research question was, "How do clinical oncology RNs describe their experiences of CF?"

Conceptual framework. A conceptual model, called the stress process model, which considers caregivers' stress in four domains is the framework for this study. The four domains are: the background and context of stress; the stressors; the mediators of stress; and the outcomes or manifestations of stress (Aneshensel et al., 1995). This model specifies multiple aspects of caregiver stress including primary stressors arising directly from patient-interactions and secondary stressors that result because of circumstances outside of the care giving situation. The model proposes that background and context influence stressors and outcomes. Mediating conditions are thought to influence intensity of stressors and the success of outcomes and these conditions have an impact on the relationship between stressors and outcomes. In all, background and contextual factors, stressors, and mediators interact to produce outcomes that lead to health and mental health consequences for the caregiver (see Figure 1).

Sampling and recruitment. Prior to recruitment of participants, ethical approval for the study was obtained from the Athabasca University Research Ethics Board (AUREB). Study participants were clinical oncology RNs, defined as nurses who have an expanded education focused on cancer care and who spend the majority of their work time providing care to patients with cancer (CANO, 2009). Nineteen study participants were recruited from across Canada through an advertisement placed in CONJ. Inclusion criteria incorporated being currently employed as clinical oncology nurses, having experienced CF as defined by LaRowe (2005), Internet access, and ability to communicate in English or French. A summary of participant demographics is presented in Table 1.

Data collection. Potential participants responded to the national recruitment advertisement by going to a secure research website developed specifically for this study where they consented to participate in the study, completed an online questionnaire, and wrote a narrative describing a time they had experienced CF. All data were then submitted to the principal investigator (PI) electronically and anonymously through the Athabasca University server which removed the submitters' IP addresses. Data (raw and analyzed) were stored in password protected computers and on locked back-up systems and were electronically shredded (using Shred 2) by the PI after data analysis. All data were handled according to the ethical guidelines required by the AUREB.

Data analysis. The research team included the PI who had expertise in oncology nursing and CF, a Master's of Nursing student with beginning expertise in qualitative data analysis, and a clinical oncology RN. Data were read and re-read by the research team members individually. Significant statements, and the possible meaning of each, were identified by each team member. During this initial reading, researchers attempt to hold in abeyance their presuppositions about the phenomena, so that the phenomena could be seen as they are, not as they are reflected through preconceptions (Oiler, 1986). Once team members had considered the data independently they worked as a team to organize the meanings into themes, and results were integrated into a preliminary description of the phenomena (Oiler). There was agreement between researchers on the themes and in the rare instance where there was no immediate agreement consensus was eventually reached through dialogue and continued discussion. Data were managed using Word.

Data trustworthiness and limitations. To increase data trustworthiness (credibility and validity) the nurses' comments are presented verbatim (Lincoln \& Guba, 1985). The sample provided a diverse population (within the inclusion criteria). This increases data credibility as a more comprehensive description of the phenomena under study occurs because of multiple viewpoints being included (Loiselle \& Profetto-McGrath, 2004). The researcher's credibility is also a consideration in securing data trustworthiness as in qualitative studies the researcher is the data collection and analysis instrument (Loiselle \& Profetto-McGrath). The PI has experience conducting Internet based qualitative studies. To achieve confirmability the PI and RAs reviewed all data sources independently, then consulted to continue analysis. This, combined with an audit trail that was part of the research design, helped promote data confirmability. The audit trail includes raw data, data reduction and analysis products, and a journal of process decisions, intentions, and questions that arose during the study. The small sample size is a limitation as the 19 respondents are only a small percentage of the total number of oncology nurses in Canada.

\section{Findings}

Findings are organized into five major themes. Illustrative comments appear in Table 2.

Theme 1: Defining compassion fatigue. Respondents provided moving examples of experiences they defined as $\mathrm{CF}$, yet they reported having limited knowledge regarding $\mathrm{CF}$ and questioned whether or not they were experiencing CF. Some said that they were not aware of the term CF, or if they had heard it, they did not know exactly what it meant or how it differed from other experiences such as burnout.

Aycock and Boyle (2009) found that CF is vaguely defined yet it is "conceptually known by oncology nurses" (p. 183). As we reviewed the study participants' narratives, it became clear that their experiences could help us to "define" what CF is for oncology RNs. Commonalties in the nurses definitions of CF included, an overwhelming sense that "something was wrong," difficulty motivating themselves to go to work, being emotionally sensitive, and fatigue.

Theme 2: Causes of CF. Apparent causes of CF in this study population included lack of support, lack of knowledge about $\mathrm{CF}$, and lack of time/ability to give high quality care.

\section{Lack of support}

Perceived lack of support seemed related to the onset of CF. RNs expressed a need for support from peers, colleagues from other disciplines, and administrators. Continued perceived lack of support over time seemed to accentuate the experience of CF.

Many nurses wrote about others having high expectations of them, which they suggested led to the belief that they were "so strong" that they did not require the support of others. Further, some nurses noted that they were reluctant to admit they needed support, feeling a need to project a sense of strength and invincibility. This combination of high expectations from self and others and limited perceived support seemed to be a precursor for CF (see Table 2).

\section{Lack of knowledge about CF}

Lack of knowledge about CF was seen by the nurses as a cause. One respondent wrote, “It wasn't until fairly recently that I even heard of compassion fatigue." Another noted, "We need to know 
more about CF so we can protect ourselves." Some respondents said the lack of acknowledgement of the potential for this experience may have made the situation worse for them. Specifically, when they began to experience symptoms of $\mathrm{CF}$, instead of considering that they might be experiencing a "natural" response to continued exposure to the suffering of others, they began to think there was something wrong with them. Participants' comments that had they known more about $\mathrm{CF}$, and anticipated that it might affect them some time in their careers, they would have been able to take preemptive positive steps to deal with it when it first became an issue rather than waiting until they were experiencing more advanced debilitating CF.

\section{Lack of time/ability to give high quality care}

Many respondents noted times when they were not able to provide patients with top-notch care, as experiences that precipitated CF. Wrote one RN, "I cry when I leave work sometimes because I feel like I couldn't give the quality of care I wanted to give." High quality care involved time to connect with patients and families. The nurses noted that they have less time to develop this connection with changes to workload and the organization of care delivery.
Theme 3: Factors that worsen CF. Respondents reported factors that worsened CF including being unable to ease suffering, co-existing physical and emotional stresses, and excessive emotional attachment and involvement.

\section{Being unable to ease suffering}

When nurses felt like there was nothing they could do for their patients who were suffering, CF was accentuated. They described feeling "helplessness." Many nurses chose oncology nursing because they had a desire to "help people who really needed their help." When they found themselves unable to help, they felt dissonance that worsened CF.

Co-existing physical and emotional stresses outside of work

In some instances, nurses described other physical and emotional struggles that they were experiencing outside of work as worsening CF. For example, one nurse described how personal health situations left her more vulnerable to work-related CF. Another respondent also linked her home-life stressors to the experience of $\mathrm{CF}$ at work. One nurse recognized that combining home and work stressors resulted in personal health issues that required intervention to pre-empt "full-blown compassion fatigue."

\section{Table 2. Illustrative participant comments}

\section{Defining CF}

- I just didn't have the energy to keep going. I remember visualizing walking through the doors and going to report and thinking I can't do it, but somehow I would manage to get there. It was sometimes a real psychological battle to do so. I felt defeated by my work and just lacking the ability to go on. You know I had no spark left. I cry easily at things in life that don't deserve tears.

- I just had an overwhelming fatigue that I couldn't get rid of no matter how much I slept.

- The feeling of hyper vigilance-where my pulse is a bit higher, blood pressure too probably, where I am "ever ready?" If there was a loud noise I may hit the floor running. Is this CF?

\section{Causes of CF}

1. Lack of support

- I supported "my" families. But did I support myself? Did anyone support me? Looking back, I think not

- Somehow I viewed myself as... "Super nurse." I had the ability to do more, withstand more, help more... more, more, more without help... It took its toll.

2. Lack of knowledge about $\mathrm{CF}$

- Compassion fatigue looms over the unit, yet no one can effectively address this phenomenon. We have barely heard of it. Is it something we should be concerned about? It's like we are blind to the potential of compassion fatigue in our lives.

3. Lack of time/ability to give high quality care

- I don't get as many opportunities to really connect with my patients and their loved ones. I spend more time "supervising others" and less time doing the work I loved to do-actually taking care of people. That is when I find myself more tired at the end of the day.

- I don't think I will escape this cloud of compassion fatigue until I get a chance to get back to really connecting with people, the reason I became a nurse in the first place! I need to give the best care and I don't have time.

Factors that Worsen $\mathrm{CF}$

1. Being unable to ease suffering

- Feelings of hopelessness and emptiness were my baggage... The unit that had once empowered me now gave me feelings of hopelessness and my compassion fatigue got worse.

- I went into cancer nursing because these people really need help and I wanted to help them... When I can't help them, either because they won't let me or because they are really sick and suffering, that is when I feel like I might be in the wrong specialty. Compassion fatigue takes over.

2. Coexisting physical and emotional stresses

- I can't really point to one patient situation that brought me to my knees. Maybe it was just... a lot of stressors coming together at once.

- When my son was in heart failure waiting for a heart transplant, my marriage was failing, my sister died with ovarian cancer, and my brother was in a car accident, I needed to step back and suffer my own tragedies rather than live the tragedies of others or I would have been in serious compassion fatigue.

3. Excessive emotional attachment/involvement

- I really start to feel for some patients. I pick up on their emotions and keep them. They follow me home at night. Even if I have a day off I keep thinking about them. It means I don't have any "free space" left in my head to really get into the other fun activities I am hoping to enjoy. Sometimes I admit I am too attached for my own good.

- When you see patients doing poorly it really affects you. If you have become too attached to them and made them like your own family it is a problem. 
Excessive emotional attachment/involvement

While most respondents noted that part of their career satisfaction came from "connecting" on an emotional level with patients and their family members, their narratives also contained descriptions of times when they experienced "excessive" emotional attachment. The respondents concluded that these situations might have contributed to their experiences of $\mathrm{CF}$.

Theme 4: Outcomes of CF. The outcomes of CF included profound fatigue, negative effects on personal relationships, and nurses who considered leaving the profession.

\section{Profound fatigue of mind and body}

Many noted fatigue was the first sign that something was wrong. The fatigue was profound, progressive, and included physical and emotional tiredness. One $\mathrm{RN}$ commented that fatigue precipitated even more fatigue until it was what she called a "cycle of fatigue." The profound fatigue included physical and emotional responses such as, "heaviness in the chest," "lumps in the throat," "foggy memory," and "holding back tears." Nurses reported that when they sought medical intervention for this fatigue, no physiological causes were found.
Negative effects on personal relationships

CF seemed to have negative effects of the nurses' personal relationships. One respondent linked her CF with the dissolution of her marriage. Respondents attributed work "distraction" with robbing them of emotional energy needed to establish and maintain family/friend relationships. Nurses with CF often chose isolation. They spent less time in leisure activities with others. They noted they became cynical and seemed uninterested, which negatively affected relationships.

\section{Considering leaving}

Many respondents said explicitly that CF caused them to consider leaving oncology nursing or the nursing profession altogether. One said, "I really don't know if I can do this for the rest of my working life." Another RN commented, "I just feel I am not making the difference that I wanted to make when I signed up to be a nurse. Maybe nursing isn't for me." Some respondents had already changed nursing roles due to $\mathrm{CF}$.

Theme 5: Circumstances that lessen CF. Respondents identified factors that helped to lessen CF including colleague support, work-life balance, connecting with others, acknowledgement, and maturity and experience.

Table 2 continued from page 94.

\section{Outcomes of CF}

1. Profound fatigue of mind and body

- I began to not feel as strong. The constant pain and suffering along with seeing people die was affecting me personally. I couldn't remember ever feeling so exhausted.

- I had lost the feeling of "fullness" that I once had while nursing on this unit. I didn't want to take on any nursing challenges on the unit. The drive just wasn't there. I was too totally tired.

2. Negative effects on personal relationships

- Perhaps my heart is damaged by CF. It is so busy being compassionate it doesn't have room for a real [personal] relationship?

- My daughter always asks, "What's wrong, Mommy?" I know it is my work. But I don't tell her.

3. Considering leaving

- I certainly was feeling like it wasn't the right career for me. I felt like I should go into real estate or something just to get away from the pain I experienced witnessing sadness.

- I ended up changing jobs, but the new job involved oncology patients as well. I am still in my "element of nursing" but removed from the intimacy of bedside care. It helped me cope.

Circumstances that Lessen CF

1. Colleague support

- I work with a great team and we take care of each other. We work hard together and when we have a particularly difficult case we grieve together, too. This makes all the difference.

- My friends at work help me to carry it from time to time, like I help with their collar of compassion fatigue when it gets too heavy.

2. Work-life balance

- When I started to feel overwhelmed I took a small step back. To be effective at work, I need to keep my other life intact, too. Balance is the key.

3. Connecting with others

- I love to play and laugh. I work at being that way-and it makes me feel better. I love my friends. Making time to share with them is everything. They make things better.

- Establishing caring relationships with people I care for. That both makes CF worse, and better.

4. Acknowledgement

- The experience was tiresome and discouraging at times but every little "win" along the way, every glimmer of progress, quickly outweighed the fatigue of the experience.

- Seeing her smile... and reaching the goals we had set collaboratively made the fatigue trivial. My caring was recognized and appreciated.

5. Maturity and experience

- Once I could let go of my fairy tale belief that as a nurse I could swoop in and fix anything for anybody I was free in a sense to do the best I could and then to let it go at that. People who don't deserve to suffer do. But I know that I can make things a little more comfortable for anyone, even those who suffer long and deeply.

- Compassion fatigue can be carried on your shoulders, not as a weight to bring you down, but as a reminder of the great privilege the oncology nurse has to witness the courage and love of our patients and their families

- When that collar of compassion fatigue gets a bit heavy, I acknowledge it and remind myself of how I came to wear it and how it keeps me grounded and how it propels me forward. 


\section{Colleague support}

Respondents often mentioned words and phrases like "teamwork," "support for each other," and "caring about each other" when describing what lessened the experience of CF. They focused on emotional support they received from co-workers. Peer support and coaching was described by newer oncology nurses as important to lessening CF.

\section{Work-life balance}

Finding an effective work-life balance was described as one strategy for lessening CF. One person wrote, "I learned to try to keep a piece of me aside-lock a part of my heart away just for me and my personal life." Others emphasized the importance of taking time for themselves when they felt overpowered by work stress. They also commented that having a fulfilling life outside of work helped them to keep perspective when work became overwhelming.

\section{Connecting with others}

Having the chance to develop relationships with patients and their families helped to lessen CF. Connecting with patients involved coming to know what patients needed, and responding. The nurses said this fueled positive satisfying relationships. One nurse wrote about the role connecting with friends plays in helping her cope with her work stressors. Outside of work connections also seemed to aid in minimizing, and perhaps preventing CF for some.

\section{Acknowledgement}

Nurses noted that being acknowledged by patients, family members, peers and administrators lessened CF. One nurse wrote about a very long and challenging involvement she had with a patient. The nurse described advocating consistently for this patient and continually thinking about how to get the patient care she needed. As a result of her dedication, the nurse was acknowledged by the patient and colleagues which she found "uplifting." Acknowledgement can come in many forms. Thank-you cards, notes of appreciation, even a genuine smile the nurses claim makes their exhaustion fade.

\section{Maturity and experience}

Participants found that by gaining work experience, and the lessons that came with this, they were better able to fend off CF. Perhaps experience taught them specific interventions and approaches that they could use to help suffering people. When they were able to intervene and lessen suffering, they were less likely to experience $\mathrm{CF}$.

Nurses reported that experience helped them to gain a perspective on life that left them less vulnerable to CF. Once they embraced the reality that life is not just, and gave up expecting it to be so, they were able to move forward and do what they could to help people. One experienced RN even held the view that CF can be positive. The emotional exhaustion she admitted to feeling sometimes, she claimed, reminded her of the privileged role she has. This nurse reported that she had come to this perspective on CF after she had matured into her role.

\section{Discussion}

The stress process model (Aneshensel et al., 1995) is helpful in furthering our understanding of the themes, and provides a foundation for development of practice implications.

\section{Primary stressors}

Several primary stressors were described by participants that seem to result directly from care giving interactions. For example, exposure to patient suffering is a primary stressor. RNs described how they interacted almost daily with people experiencing physical, psychological and spiritual trauma as a result of their disease process or treatments. This ongoing contact with human suffer- ing, especially when it was in someone they closely identified with, was a primary stress. Being unable to relieve suffering was especially stressful.

\section{Secondary stressors}

Perceived lack of support by colleagues and administrators may be a secondary stressor for the RNs in this study. Other secondary stressors included circumstances in their personal lives such as difficulties with children, challenging spousal relationships, other responsibilities outside of work such as caring for aging parents or their own health challenges. These could all be identified as secondary stressors that could all contribute to the experience of CF.

\section{Mediating conditions}

While lack of support can be a secondary stressor, when support is present it can also be a mediating condition that helps to minimize CF. Experience and maturity as an oncology nurse was described as a condition that mediated the stressors and could assist nurses in handling stressful situations more effectively. In some instances the experience and maturity of the nurses allowed them to gain perspective that helped them to see their interactions with cancer patients as a positive. The presence of appropriate acknowledgement for their work was also noted by respondents as a factor that mediated the effects of stressors on them.

\section{Background and context factors}

The length of the care trajectory, the intimacy of their relationships with patients and families, the intensity of the disease and therapies are all part of the context within which oncology nurses work that may impact the level of stress and the potential for CF. In several of the narratives, the nurses described the onset of CF after they cared for patients who died.

\section{Outcomes}

The respondents all reported taking some sort of action to cope with $\mathrm{CF}$. One changed jobs, moving to a nursing role that she found required her to witness less suffering. Other nurses withdrew in some sense from the intensity of their patient relationships. Another outcome noted in some respondents was an attitude adjustment. They began embracing the reality that life is not fair and then they were able to deal more effectively with suffering. Some came to see their work as an opportunity that made their own lives more fulfilling, helping them avoid CF.

\section{Possible interventions to mitigate $\mathrm{CF}$ \\ 1. Increase education about CF}

There is a lack of education and knowledge about CF. More knowledge about all aspects of CF could be provided through preservice and continuing education. Oncology nurses need to know that they may be at risk for $\mathrm{CF}$ to promote early recognition of $\mathrm{CF}$ in themselves and others.

\section{Promotion of teamwork and collegial support}

Collegial support lessens CF and lack of support accentuates the risk. Many participants who were experiencing CF reported feeling "alone." Formal programs and policies that promote teamwork and caregiver to caregiver support are recommended. Examples of such programs include role model, preceptor, or mentor programs, or the formation of interdisciplinary teams to provide colleague support through debriefing or discussion of difficult patient situations.

\section{Develop a philosophy of "there is always something more they can do"}

Nurses experienced CF when they felt helpless to relieve suffering. Many nurses were unhappy with the quality of care they were giving and questioned if it "was enough." Feelings of "failing the 
patient" and "hopelessness" seemed to be common factors precipitating CF. Educators and administrators need to cultivate in staff the belief that there is always something they can do to lessen suffering. This philosophy of care may empower staff to think creatively and band together to try to relieve suffering. Taking action and not giving up may help to abate the sense of hopelessness that some nurses said led to CF.

\section{Discuss appropriate emotional attachment}

Emotional attachment to patients and families is an important consideration. While it brought feelings of satisfaction and purpose in some instances, other times it seemed to result in CF. Emotional involvement needs to be addressed in orientation and in ongoing professional development arenas. This is also an important topic for further research.

\section{References}

Abendroth, M., \& Flannery, J. (2006). Predicting the risk of compassion fatigue. Journal of Hospice Palliative Care Nursing, $8(6), 346-356$.

Absolon, P., \& Krueger, C. (2008). Interventions to manage compassion fatigue in oncology nurses. Oncology Nursing Forum, 35(3), 500.

Adams, R., Figley, C., \& Bascarino, J. (2008). The compassion fatigue scale: Its use with social workers following urban disaster. Research on Social Work Practice, 18(3), 238-250.

Aneshensel, C., Pearlin, L. Mullan, J., Zarit, S., \& Whitlatch, C. (1995). Profiles in caregiving: The unexpected career. San Diego: Academic Press.

Aycock, N., \& Boyle, D. (2009). Interventions to manage compassion fatigue in oncology nursing. Clinical Journal of Oncology Nursing, 13(2), 183-192.

Aycock, N., \& Boyle, D. (2008). Overcoming compassion fatigue. Oncology Nursing Forum, 35(3), 524.

Badger, K., Royse, D., \& Craig, C. (2008). Hospital social workers and indirect trauma exposure: An exploratory study of contributing factors. Health and Social Work, 33(1),63-71.

Benoit, L., McCarthy Veach, P., \& LeRoy, B. (2007). When you care enough to do your very best: Genetic counselor experiences of compassion fatigue. Journal of Genetic Counseling, 16(3), 299313.

Bush, N. (2009). Compassion fatigue: Are you at risk? Oncology Nursing Forum, 36(1), 24-28.

Canadian Association of Nurses in Oncology. (n.d.). Roles in oncology. Retrieved from http://www.cano-acio.ca/roles

Costa, D. (2005). Compassion fatigue: Self-care skills for practitioners. Occupational Therapy Practice, 10(20),13-18.

Davis, J. (1996). Sadness, tragedy and mass disaster in Oklahoma City: Providing critical incident stress debriefings to a community in crisis. Accident Emergency Nursing, 4, 59-64.

Ferrell, B., \& Coyle, N. (2008). The nature of suffering and the goals of nursing. Oncology Nursing Forum, 35(2), 241-248.

Figley, C. (1995). Compassion fatigue. New York: Brunner/Mazel.

Joinson, C. (1992). Coping with compassion fatigue. Nursing, 92(22), 116-121.

LaRowe, K. (2005). Transforming compassion fatigue into flow. Boston: Acanthus.

Larson, D. (1993). The helper's journey: Working with people facing grief, loss, and life-threatening illness. Champaign, IL: Research Press.

Lincoln, Y., \& Guba, E. (1985). Naturalist Inquiry. Newbury Park, CA: Sage.

\section{Conclusion}

This study provides knowledge about the experience of CF in Canadian clinical oncology RNs. A beginning definition of what CF is to this group of caregivers along with a discussion of factors that cause, worsen, and/or lessen CF, and outcomes of CF in this group was provided. Analysis of the findings using the stress process model led to practice recommendations that included teaching nurses about CF, structuring collegial support, development of a care philosophy that reduces the sense of hopelessness, and upfront discussion of issues around emotional engagement with patients and families.

\section{Acknowledgements}

Funding for this study was provided by the Canadian Association of Nurses in Oncology (CANO) Experienced Researcher Grant 2008.

Loiselle, C., \& Profetto-McGrath, J. (2004). Canadian essentials of nursing research. NY: Lippincott Williams \& Wilkins.

Magraith, K., Benson, J., \& Yunti, N. (2005). Compassion fatigue and burnout. Australian Family Physician, 34(6), 497-498.

Maslach, C., Jackson, S., \& Leiter, M. (1996). Maslach burnout inventory manual. PaIo Alto, CA: Consulting Psychologists Press.

McMullen, L. (2007). Compassion fatigue. Oncology Nursing Forum, 34(2), 491-492.

Munroe, J. (1995). Preventing compassion fatigue: A team treatment model. In Compassion fatigue: Coping with secondary traumatic stress disorder in those who treat the traumatized. C. Figley (Ed.). New York: Brunner/Mazel.

Oiler, C. (1986). Phenomenology: The method. In P. Munhall \& C. Oiler (Eds.), Nursing research: A qualitative perspective. Norwalk, CT: Appleton-Century-Crofts.

Perry, B. (2009). More moments in time: Images of exemplary care. Edmonton, AB: AU Press.

Pfifferling, J., \& Gilley, K. (1999). Overcoming compassion fatigue. Family practice management, 17(3), 36-42.

Pickett, M., Brennan, A., Greenberg, H., Licht, L., \& Worrell, J. (1994). Use of debriefing techniques to prevent compassion fatigue in research teams. Nursing Research,43(4), 250-252.

Pierce, B., Dougherty, E., Panzarella, T., Le, L., et al. (2007). Staff stress, work satisfaction, and death attitudes on an oncology palliative care unit, and on a medical and radiation oncology inpatient unit. Journal of Palliative Care, 23(1), 32-42.

Polit, D., \& Hungler, B. (2001). Essentials of nursing research: Methods, appraisal and utilization (5th ed.). New York, N.Y.: Lippincott Williams \& Wilkins.

Robinson, J., Clements, K., \& Land, C. (2003). Workplace stress among psychiatric nurses. Journal of Psychosocial Nursing and Mental Health Services, 41(4), 32-44.

Sabo, B. (2006). Compassion fatigue and nursing work: Can we accurately capture the consequences of caring work? International Journal of Nursing Practice, 12(3), 136-142.

Sabo B. (2008). Are you at risk for compassion fatigue? International Journal of Nursing Practice, 13(3), 136-142.

Stebnicki, M. (2002). Stress and grief reactions among rehabilitation professionals: Dealing effectively with empathy fatigue. Journal of Rehabilitation, 66(1), 23-30.

van Manen, M. (1990). Researching lived experience: Human science for an action sensitive pedagogy. London, ON: Althouse. 